\title{
Kiwis on ice: Defining the ways in which the New Zealand identity is reflected in the Antarctic-inspired works of four New Zealand composers
}

\author{
Patrick Shepherd ${ }^{1}$
}

\section{Antarctica - 'a poetical fantasy to range in'2}

With the substantial body of work which has been produced by artists all over the world from many artistic disciplines, critics are now in a good position to examine exactly what the artist's relationship is with Antarctica, both from the artists' own words and the work they have produced. Bringing the world to the continent is certainly a literal reality for those who travel to Antarctica, but the converse is also true, as each artist brings the continent back to the world. It may also be true that Antarctica is the ultimate silence, a blank canvas upon which each artist can project their own imagination. Interpreted differently, it may be the ultimate silence because of the unique challenges it offers, what Pyne describes as 'an esthetic sink, not an inspiration. Its landscape erased those elements which provided worlds accessible, and its fantastic isolation seemingly defied any but self-referential attempts to assimilate it' ${ }^{3}$

In looking at how the New Zealand artists relate to Antarctica - and in particular the four composers discussed in this paper - it is perhaps helpful to ascertain first what drivers New Zealanders exhibit. To merely describe the Kiwi relationship with Antarctica as 'unique' is unhelpful. To paraphrase Animal Farm, 'Everyone is unique; we're just more unique than them', says little about how one country relates to the continent. On a practical level, there are the obvious geographical, political and economic links, but they are hardly unique. The historical links such as Lyttelton and Timaru - places the heroic

1 Dr Patrick Shepherd, College of Education, University of Canterbury, Private Bag 4800, Christchurch, New Zealand, patrick.shepherd@canterbury.ac.nz.

2 A Kippis (1788) The life of Captain James Cook. Printed for G Nicol and GGJ and J Robinson, London, p. 510.

3 SJ Pyne (1986) The Ice. Phoenix, London, p. 150. 
age expeditions of Scott departed from - have certainly helped cement a strong bond between the two places, as has a bona fide local Telecom (now Spark) dialling code for New Zealand.

New Zealand was also one of the countries to set up education, artists and writers programs. The New Zealand government was a signatory to the Antarctic Treaty. The Gateway Antarctica program continues to flourish at the University of Canterbury where, incidentally, the Council of Managers of National Antarctic Program currently resides. Of course, the Erebus disaster of 1979 where a sightseeing plane crashed into Mount Erebus killing all 257 people on board is still very raw in the Kiwi psyche.

\section{Key indicators for the New Zealand identity}

Antarctica provides the ultimate wilderness for a country whose residents exhibit a world-renowned sense of adventure and travel, as well as a love of the outdoors and nature. New Zealand is an eco-friendly country, as well it might be, for if climate change becomes a terminal reality and Antarctica reduces in size through melting, New Zealand will be one of the first places to be affected. Given all these factors the Kiwis' near-obsession with their relationship to the land is hardly surprising, particularly in the strong cultural and spiritual ties exhibited by the Maori.

The relationship with the land is argued for strongly in the album Home, Land and Sea (Trinity Roots 2004). Situating music in Aotearoa New Zealand ${ }^{4}$ follows on from Glenda Keam's PhD thesis on the notions of national style in contemporary New Zealand music, of which landscape plays a significant part. Douglas Lilburn, the grandfather of modern New Zealand art music, believed that the land and the environment could contribute to a national musical style that he felt was missing. He also believed that there was a process whereby New Zealand composers were being subconsciously formed and creatively affected by the land and the environment, as evident in his claim that 'this environment of ours is shaping us into characteristic rhythms of living' ${ }^{5}$

Of course, when all else fails, New Zealanders blame Australians, so perhaps the whole New Zealand obsession with national identity in music was in part due to Percy Grainger who spoke on New Zealand radio in 1935 giving New Zealand composers their cue to look to the landscape for musical significance,

4 Glenda Keam and Tony Mitchell (2011) Home, land and sea: situating music in Aotearoa New Zealand. Pearson New Zealand, Auckland.

5 Keam and Mitchell (2011), p. 218. 
announcing that he would be awarding a prize for the best composition by a New Zealand-born composer that presented 'typical New Zealand cultural and emotional and characteristics' ${ }^{6}$

Several recent studies of New Zealanders have shown that top of their list in importance is a love of, and respect for, the environment - KEA (2011), Practica (2010), Timezoneone Blog (2009), NZ Herald (2008). Practica's research — as reported in Jane Clifton's article 'Choice, bro' ${ }^{7}$ — identified seven 'legends' (defining characteristics) for New Zealanders: relationship with the land, independence and freedom, masculinity of expression, importance of sport, 'mateship', being easy-going and non-confrontational, and a sense of humour. Of these, perhaps 'masculinity of expression' and 'mateship' provide some of the more subtle identifiers between Antarctica and New Zealand, a place to get away from it all with your mates in much the same way as the hunter or fisherman might trek off into the bush or high country for days on end.

On a slightly less formal note - and out of the mouths of babes, as so often the simple truths are - one need look no further than the website of Mrs Brunton's Year 8 class in room 28 at Marina View School who came up with, 'To me, being a Kiwi means that you box above your weight'; 'It means NZ has no pollution, great greenery, great oceans. Kiwis have freedom'; 'We have the chance to achieve great things'; and finally, 'To watch the All Blacks versus the Wallabies' ${ }^{8}$

New Zealand's relationship with Antarctica may also be seen as part of a 'coming of age'. In much the same way as the British Empire regarded it in the heroic age, so Australia and New Zealand claiming their parts of Antarctica has been part of those countries' coming of age. Nazi Germany also saw it as strategically desirable, establishing a base there during World War II, and the Americans currently have a military presence, albeit benign. Hollywood has done much to cement Antarctica in the popular culture through movies such as The Thing and Alien vs Predator which choose the brutal isolation of Antarctica on which to project the drama.

\section{Artist programs}

The US, Australia, New Zealand, United Kingdom, Chile and Argentina are some of the countries that run - or have run - Antarctic artist schemes. From all the different countries a significant body of Antarctic-related art has been

6 Keam and Mitchell (2011), p. 219.

7 New Zealand Listener (Online), 3 Jul 2010, vol 224(3660) issn:0110-5787.

8 http://www.marinav.school.nz/Site/Archive/2007/Team_Brunton/Room_28_-_Mrs_Brunton_-_Year_8. ashx, retrieved 19 June 2011. 
established. The artists who have headed to Antarctica from New Zealand have not always done so through government-assisted schemes. The practice started in 1957 with painter Peter McIntyre and, later in 1970, with Royal New Zealand Air Force official artist Maurice Conly. The New Zealand Artists to Antarctica scheme (and a parallel education scheme) ran from 1997 to 2007 in conjunction with Creative New Zealand, New Zealand's main arts funding body. Currently, two to three artists are selected annually by a panel and 'shoulder-tapped'. The 45 artists New Zealand has sent to Antarctica represent most artistic disciplines: painting, sculpture, musical composition and performance, furniture-making, choreography, play and novel writing, poetry, photography, fashion design, ceramics, printmaking, jewellery, and textile art. The Postgraduate Certificate in Antarctic Studies, part of the University of Canterbury's Gateway Antarctica program, has also seen several artists including Laura Taylor (Antarctic Lullaby) and Julian Evans (ice pipe installation) head south as part of their studies.

\section{The four composers}

The four composers who are the subject of this paper are Chris Cree Brown, Phil Dadson, myself and Gareth Farr. They are listed in the order in which they travelled to Antarctica, Chris Cree Brown being the first, with the musical excerpts played during the oral presentation at the conference listed at the start.

\section{Chris Cree Brown}

Under Erebus (2000) — electroacoustic

Icescape (2003) - symphony orchestra

I had hoped to find sounds whose morphology and spectra I could digitally transform to create abstract sounds that would reflect some of the magnificence of the continent. This would create an expressive link between a real, unaltered and recognisable sound source and more abstract textures.

My goal was to create an expressive work of sonic art that reflected my personal interpretation of the environment of Antarctica and my experiences while in Antarctica.

Prior to going down to the Ice, I classified the Antarctic sounds into four different categories: 
i) Environmental sounds: ice cracking, breaking and rumbling on the Erebus ice tongue, tapping ice crystals, ice crystals shattering, and the various types of wind (polar wind, Antarctic white out, katabatic wind).

ii) Wildlife: various species of penguins, skuas, petrels and underwater vocalisations of seals.

iii) Human activity: the effort in walking (panting), the squeaking of footprints on snow (the snow in New Zealand is not dry enough for this sound), ice breakers and the radio communications.

iv) Silence.

Such a significant experience as Antarctica is bound to influence one in a myriad of ways, and the Antarctic experience has allowed a new perspective on environmental issues, and the fragility of our planet.

One of the striking aspects of the Antarctic sound world is the apparent incongruity of many sounds when compared to the environment. The massive, majestic icescapes and graceful, sweeping glaciers evoke a music that embodies grand, slow moving, dense and interweaving textures. These characteristics seem to be the antithesis of the sounds that are heard on the continent.

The Antarctic Treaty acknowledges sound ecology and has set aside some few thousand square miles where mechanical and other human noise is prohibited. Ours is a world where noise (defined here as the undesirable sonic by-product of human activity) and its insidious psychological consequences on humanity has largely been ignored. In the words of Canadian sound ecologist, R Murray Schafer, It would seem that noise pollution has reached an apex of vulgarity in our time'.

Antarctica, by contrast, appears as a near pristine environment, not only with regard to its visual and physical environment, but also in its sonic landscape. The tranquility in Antarctica is unfamiliar and, as a consequence, marginally disturbing, especially when exacerbated by the absence of ambient sound. The sociological, psychological and cultural changes that have occurred as a direct consequence of the unrestrained increase in and excessive intensity of noise pollution must be profound. However, it is reassuring that our species has saved some small piece of the planet in terms of sound ecology, even if there is nothing there except ice.

There is little doubt that when tourism in Antarctica becomes further established, a corresponding quantity of noise will ensue and, as elsewhere on the planet, assume a low priority in the pollution stakes. 


\section{Phil Dadson}

Flutter (2004)

Stonemap (2005)

Chthonian Pulse (2005)

Excerpts played from Polar Projects (Flutter; Stonemap; Aerial Farms; Echo Logo)

Any preconceptions I did have were made up of mental images conjured from reading explorer accounts and from photographs, all fairly typical. The actual experience far surpassed any imaginings, especially those in the Dry Valleys. Nothing prepared me for the pristine temple-like atmosphere of one stone valley floor in particular, which I nicknamed 'valley of the gods'. Wind-sculpted granite ventifacts, some strangely anthropomorphic, surreally backgrounded against giant dunes of black sand banked half way up one hundred foot high crystalline walls of ice.

The Antarctic experience was one I went into with all antennae bristling, heightened somewhat by the prosthetics of a camera lens and a highquality microphone. Above all, it reinforced for me the attitude of going into a situation with as few preconceptions as possible; keeping an ear and eye out for sounds and sonic images that might catch my attention, and welcoming the unexpected - the 'improviser' sensibility.

I was making field recordings with a Uher tape recorder around the same time I first got interested in composing, and then later as a filmsound recordist, so the tape-recording medium and structuring and editing processes have always been part of my compositional thinking. I don't make any separation really, between the act of composing in one medium or another - whether it's film, video, audio, an installation, a music ensemble or combinations of - the process for me is very similar.

Summertime, January 2003, and a $24 / 7$ period of daylight. I was going out filming and recording most nights around 8 or $9 \mathrm{pm}$ and returning to the tent site at 3,4 or 5 in the morning. The light at so-called 'nighttime' was so much better for recording video. It was like continuous early morning or late afternoon light, devoid of the harshness of full daytime sunlight. The sun would appear to strike a medium arc across the sky during the main hours of daytime and then, at late afternoon appear to just sit at one level close to the horizon line and remain there. I was recording ice cracks for one entire night (without too much luck I have to say) and during this time sat motionless, simply watching and listening, much of the time focused on my relationship with the planet 
and to the sun. Instead of watching the sun slowly creeping along the horizon line, I could literally sense the earth turning around the sun. It was a simple and profound sensation and it has stayed with me.

Polar Projects is as much a composition of elements, from my perspective, as an installation. One [memory] I regularly return[ed] to was the physical sensation of feeling an absolutely minuscule remote and insignificant dot on the surface of the planet, and at the same time, awestruck with a physical sensation of the me as a tiny dot on the earth turning around the sun.

It's a rare opportunity and one that should be available to as many artists as possible. Another time, I'd like to do a sequel that interfaced more intentionally with specific locations, and with science teams as performer/ collaborators, maybe via another nation's program. It's provided a heightened sense of urgency about the politics of impermanence. It's also polished the lens through which I view landscape and geography.

\section{Patrick Shepherd}

Katabatic (2005) — chamber ensemble

Adeliesong (2005) - two clarinets

Fanfare for a Frozen Land (2005) — orchestra

Cryosphere (2005) - orchestra

I've always loved the ice and snow. Coming from the north of England some of my earliest childhood memories are associated with snow that amazing light you sense when you first wake up and it's lighter, brighter and crisper than it usually is. I needed inspiration and thought Antarctica might be interesting. I knew Chris [Cree Brown] had gone and he reckoned it was life-changing so I decided to give it a go. I didn't expect it to become an all-consuming passion.

Conrad's Heart of Darkness is often used as a metaphor for Antarctic - and Arctic - exploration, and I think that anyone who goes there faces the ultimate truth that in an environment stripped bare of virtually everything there really is nowhere else to run to - it's you and nature, face-to-face. Shackleton got it right when he said that Antarctic exploration was not an outward journey but rather an inward journey of discovery. 
It's really hard to try and see a stylistic change in my music, perhaps because I'm too emotionally and chronologically close to the event. Besides, people who claim they've 'changed' rarely have. I'm not concerned as much with my audience, maybe. Don't get me wrong, I want to connect but I'm less concerned with the performance playing out in my head as I write and more with the effect of the sounds. I still write at the computer but I tend to sketch first on paper; there's a freedom of expression there that you just don't get on the sequential thinking of the computer.

I'm up the top of Observation Hill, which separates Scott Base from McMurdo Station. It's snowing, I'm scared stiff because I've just climbed up a steep hill having not told anyone where I am (an absolute no-no down there) and I'm looking at the jarrah cross that bears the famous quote from Ulysses in memory of Scott and his four doomed companions. I was very proud to be British, very proud to be a Kiwi and ecstatic that I was an Antarctican. Anyone who calls Scott an idiot misses the point - there's some stuff in life bigger than life itself and dying might be the last thing that happens to you but it may not be the worst.

I expected to come away so full of inspiration that the artistic juices would flow freely. Instead, I got a kind of block which lasted for over six months. Science - that was my only way through. I had a kind of block, the subject matter was so big and there's only so much stuff you can write that sounds like Arvo Pärt, so I moved away from the purely descriptive and found inspiration in the little things, the minutiae, the scientific stuff - and the human interest aspects. I started on Katabatic - which was a 30 second microscore - to get me working, then I moved on to Adeliesong, replicating the additive rhythm call of the penguins, which I then orchestrated out into Fanfare for a Frozen Land. The layering of the orchestration in Cryosphere took its inspiration from using a Kovacs drill on field training at Scott Base and seeing the different strata of ice and debris.

Stephen Pyne's book The Ice was brilliant. When you're there the beakers (scientists) tend to regard the artists as a bit 'arty-farty' (which we know can be true) but we also end up putting a human and a more publicly accessible front to much of the hard science they're dealing with. If we (the artists) can bring the issues closer to people, particularly in schools, we might have a chance of getting science front and centre, too. 


\section{Gareth Farr}

Terra Incognita (2007) - tenor, chorus and orchestra

There are two overwhelming things that hit you in the face when you go to Antarctica. The first is that the world is a very scary place. It's fierce, unrelenting, and non-negotiable. The second is that the world is a very fragile place. If something that appears so invincible, so powerful, and so eternal can be falling apart because of what us humans have done in the last hundred years or so, then we have really screwed up badly.

I went to Antarctica with the expectation of discovering a landscape, a physical geographical experience - but returned to New Zealand having not only experienced that, but also a foreign culture, in exactly the same way as I have in the US, in Indonesia, in Australia. There is Scott Base, which is obviously profoundly Kiwi, and there is McMurdo Station - five minutes away by road - which is just like being in the US - currency, accents, everything. But there is an overriding Antarctic culture there - an understanding of things that they all have in common that are utterly peculiar to Antarctica - such as safety/ survival issues, scientific issues, general things you just have to know to exist in a space station-like environment.

I don't think my compositional style has altered because of Antarctica per se - writing a piece for bass voice and orchestra taught me a huge amount about balancing a singer with an orchestra, which will impact on every piece I write for singer (or any soloist for that matter) and orchestra in the future. It also was my first major dramatic piece, where I had to look at the piece as a piece of theatre, and structure/pace it accordingly.

I'm not a word person - I'd be an author otherwise — it's not my talent to put an experience into words. I've always hated the idea of expressing landscape in music - in fact I've never been that keen on expressing anything visual in music - because I don't think that music exists for that purpose. Music is music. I don't even like writing program notes - to me they seem like an apology because the music wasn't capable of communicating to the audience.

So to write a piece of music inspired by my experience in Antarctica was utterly impossible, based on my self-imposed restrictions! But there was a moment — the epiphany moment! — when I realised that it was the people who have been to Antarctica in the last hundred years; that is what I can reflect in my music. 
Basically what happened is that the minute I realised the project was about people and their relationship to the continent, as opposed to a musical representation of the geographical features, I had a major epiphany. I had talked to Paul Whelan (Kiwi singer, then based in London) about a piece a few years earlier, and we had in mind a piece for bass voice and orchestra - but as always happens the idea had fallen by the wayside because neither of us had the funding to do anything. The epiphany was - 'oh my God, this is the piece - I need the epic sound of an orchestra, and I need the human communication of a singer — this is the piece!'

My general outlook changed in a very specific way - ecologically.

\section{Conclusion}

The experiences of the four New Zealand composers demonstrates not only how their personal horizons broadened but also how the journey south offers a unique opportunity to compare and contrast their work in a unique way. It is indeed rare to be able to make such direct comparisons between the works of people operating in a similar discipline exposed to exactly the same stimuli and as such provides an invaluable insight into not only how the creative mind operates but also how art interacts with life on the ice. 
This text is taken from Antarctica: Music, sounds and cultural connections, edited by Bernadette Hince, Rupert Summerson and Arnan Wiesel, published 2015 by ANU Press, The Australian National University, Canberra, Australia. 